\title{
A Bayesian analysis of associations between neighborhoods, spanking and child externalizing behavior
}

\author{
Andrew Grogan-Kaylor ${ }^{\mathrm{a}, *}$, Berenice Castillo ${ }^{\mathrm{a}, \mathrm{c}}$, Julie Ma ${ }^{\mathrm{b}}$, Kaitlin P. Ward ${ }^{\mathrm{a}, \mathrm{c}}$, Shawna J. Lee ${ }^{\mathrm{a}}$, \\ Garrett T. Pace ${ }^{\mathrm{a}, \mathrm{d}}$, Jisu Park ${ }^{\mathrm{e}}$

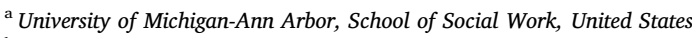 \\ ${ }^{\mathrm{b}}$ University of Michigan-Flint, School of Social Work, United States \\ ${ }^{\mathrm{c}}$ University of Michigan, Department of Psychology, United States \\ ${ }^{\mathrm{d}}$ University of Michigan, Department of Sociology, United States \\ ${ }^{\mathrm{e}}$ Sungkyunkwan University, Department of Child Psychology and Education, South Korea
}

\section{A B S T R A C T}

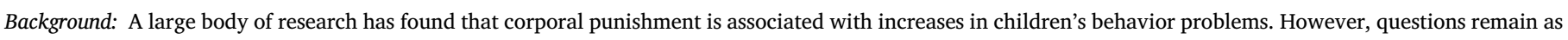
to whether or not the relationship between corporal punishment and behavior problems is equally true across contexts.

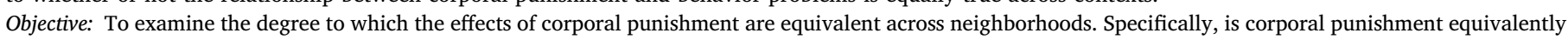

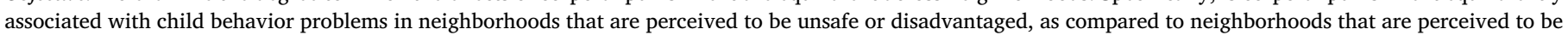
less disadvantaged?

Participants: 2703 participants in the Fragile Families and Child Wellbeing Study.

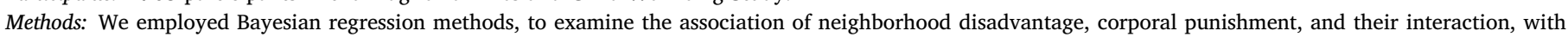
child behavior problems.

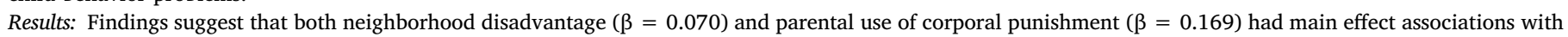
child behavior. However, there was no evidence for an interaction of neighborhood disadvantage and corporal punishment use.

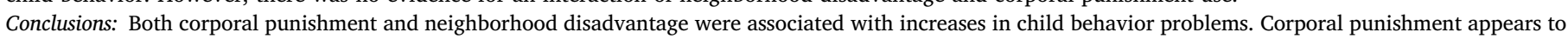
be equally deleterious across neighborhood contexts.

\section{Introduction}

To date, studies examining the conditional physical punishment arguments have largely focused on socio-demographic characteristics (e.g., parental race and ethnicity) and dimensions of the parent-child relationship (e.g., parental warmth, parental impulsivity). For example, a perennial debate in the research on physical punishment has been the role of parental race and ethnicity, with one key early study suggesting that White children may be more harmed by exposure to parental physical punishment than Black children (Deater-Deckard et al., 1996). However, a rigorous meta-analysis (Gershoff \& Grogan-Kaylor, 2016b) and multiple recent studies (e.g., Gershoff, Sattler, \& Ansari, 2018; Grogan-Kaylor et al., 2018; Ward Lee, Limb et al., 2019) showed no support for differential effects of parental physical punishment as a function of race and ethnicity. In other words, there was no evidence indicating that race and ethnicity moderated the associations between parental physical punishment and child outcomes, with research indicating small but statistically significant associations between physical punishment and adverse child outcomes across racial and ethnic groups (Gershoff \& Grogan-Kaylor, 2016b).

Another important facet of the parent-child relationship is parental warmth and attachment, or parenting behaviors that confer affection, comfort, support, and love to the child (Rohner, 2004). Researchers have argued that parental warmth may serve as a moderator of the effects of physical punishment on children (Baumrind, Larzelere, \& Cowan, 2002; Benjet \& Kazdin, 2003; Darling \& Steinberg, 1993). In other words, high levels of parent-to-child warmth may buffer children from negative consequences of parental physical punishment. However, again, studies suggest that neither parental warmth nor attachment moderates the associations between parental physical punishment and child behavior problems (Berlin et al., 2009; Lee et al., 2013; Stacks et al., 2009; Ward, Lee, Pace et al., 2019b).

Early studies focused on examining proximal components of the parent-child relationship as potential moderators of the associations between parenting behaviors and child wellbeing However, as posited by the Developmental Ecological Model (Belsky, 1993), the

\footnotetext{
* Corresponding author at: School of Social Work, 1080 South University Avenue, Ann Arbor, MI 48109, United States.

E-mail address: agrogan@umich.edu (A. Grogan-Kaylor).
} 
neighborhood context is yet another determinant of child wellbeing (McLoyd, 1998). In the current study, we employ a Bayesian regression analysis in order to examine whether neighborhood risk moderates the association between maternal physical punishment and child externalizing behavior.

\section{Neighborhoods, physical punishment and child behavior}

Recognizing the important potential influences of neighborhood conditions on parenting processes, researchers have recently questioned whether neighborhood conditions-such as high levels of poverty, crime and community disorganization-may also function as potential moderators of the association between parental physical punishment and child aggression. This line of reasoning questions whether neighborhood contexts may heighten or reduce the risk of physical punishment on children (e.g., Eamon, 2002; Earls, McGuire, \& Shay, 1994; Furstenberg, 1993; Garbarino, Kostelny, \& Barry, 1997; Ma et al., 2020).

Conceptually, an area of research contends that harsh parenting-characterized by the use of punitive child-rearing practices, such as physical punishment-is more normative in disadvantaged contexts (Friedson, 2016; Simons, Whitbeck, Conger, \& Wu, 1991). Consequently, the effects of physical punishment may not be as detrimental, and might plausibly be beneficial, to children in neighborhood contexts in which crime, social disorder and gang activity are prevalent. Due to the serious consequences of children's misconduct in these highrisk neighborhoods, it is sometimes speculated that parental physical punishment may protect children from harm or injury by ensuring their obedience and preventing misbehaviors and, in the long run, serve a protective function for children.

However, to date, there is little empirical testing of this theory. In a study of 10-12-year-olds from the National Longitudinal Survey of Youth (NLSY), Eamon (2002) found that physical punishment predicts lower levels of externalizing behavior in neighborhoods with higher levels of crime, violence, and disorder. Other studies that have employed more rigorous statistical approaches such as fixed effects regression (Grogan-Kaylor, 2005; Ma et al., 2020) and multilevel modeling (Simons et al., 2002), which also included stronger statistical controls, found that the relationship between corporal punishment and negative child outcomes did not differ by neighborhood conditions.

Statistically and conceptually, the interaction of parenting behaviors-namely, physical punishment-and neighborhood conditions might most easily be thought of in terms of the intercept and slope of children's behavior problems. The literature on multi-level modeling of longitudinal data refers to the differing interpretations that can be given to different changes in the intercept (main effect), or changes in the slope (interaction; Raudenbush \& Bryk, 2002). However, we are not aware of instances in which this differentiation of slope and intercept has been rigorously applied to non multi-level analyses of the interaction of neighborhood and parenting. Various possible combinations of main effect and interaction are conceptualized in Fig. 1.

In Fig. 1, we conceptualize the slope for the association of physical punishment and behavior problems in a reference, or less disadvantaged neighborhood, to be positive (panel 1). That is, congruent with recent summaries of the research literature on physical punishment (Gershoff \& Grogan-Kaylor, 2016a), we imagine that increases in parental use of physical punishment would be associated with increases in child behavior problems. Empirically, it is possible that the association of physical punishment with child outcomes plays out no differently in advantaged neighborhoods. As illustrated in panel 2, it may be that the undesirable effects of physical punishment are equivalent across different types of neighborhoods.

Alternatively, as previously noted, it has been hypothesized that physical punishment may be less deleterious in disadvantaged neighborhoods (panel 3). This association between neighborhood disadvantage and physical punishment could stem from physical punishment being more normative in low-income neighborhoods (Friedson, 2016; Simons, Whitbeck, Conger, \& Wu, 1991), or from parental use of physical punishment being only one of many possible forms of violence to which children are exposed. On the other hand, it is plausible that physical punishment may be a form of family violence whose undesirable effects are compounded by living in a more disadvantaged neighborhood. Thus, as illustrated in panel 4 , associations of physical punishment with child behavior problems may be stronger in high-risk neighborhoods than they are in low-risk neighborhoods.

Effects of physical punishment may also play out in terms of main effects. Panels 5 through 7 illustrate such possibilities, where physical punishment is associated with higher levels of behavior problems, sometimes in combination with a change in slope, and sometimes not. Put more intuitively, neighborhood conditions may have a direct effect on child behavior that is independent of parental use of physical punishment.

\section{Bayesian statistics and research on child development}

Bayesian statistics coincide with a preeminent goal of child development research: building upon and replicating prior research findings. The Bayesian paradigm posits that "priors" (i.e., information that was discovered in previous studies) can be integrated into a current study to inform the analyses and, ultimately, the results (Jackman, 2009; Vanpaemel, 2010). In other words, Bayesian statistics concurrently acknowledge previous findings while considering present data and provide researchers with a more well-informed finding. Thus, Bayesian theory and statistics encourages the building-upon of prior knowledge-knowledge that could be obtained from a number of different disciplines (Dunson, 2001). Research conducted under the frequentist paradigm does not allow for such prior knowledge to be incorporated into current analyses (van de Schoot et al., 2014). Instead, frequentist methods continually test and re-test the null hypothesis, limiting the interpretation of, and possibility of interdisciplinary action in, scientific replication (Kruschke \& Liddell, 2018).

Because frequentist statistics do not utilize prior research findings and, instead, rely heavily on p-values, frequentist statistics have some disadvantages when interpreting the final results of a study. The pvalue in frequentist statistics reflects the probability of attaining the researcher's estimated coefficient, assuming the null hypothesis to be true (Sterne, Smith, \& Cox, 2001). Rather than saying something about the true relationship between variables, frequentist p-values show whether there is enough evidence to reject the presumption that "nothing is happening" (i.e., the null hypothesis), or whether one fails to reject the presumption that "nothing is happening" (Morrison \& Henkel, 1970). Bayesian estimation can prove useful here, as the Bayesian paradigm is not narrowed to simply rejecting or failing-toreject the null hypothesis (van de Schoot et al., 2014).

In the current study, we embrace the advantages Bayesian estimation can offer to child development research by incorporating information from previous research into our analyses-specifically, the effect of physical punishment on child externalizing behavior. Only one prior study has used Bayesian statistical analysis to address associations between physical punishment and child wellbeing (Grogan-Kaylor et al., 2018). Incorporation of a prior is discussed in more detail below in the section detailing our analysis.

\section{Bayesian equivalence testing}

In nearly all scientific disciplines, including child development, determining whether an effect does not exist can be equally important to determining whether an effect does exist (Lakens, Scheel, \& Isager, 2018). For research questions addressing the former, Bayesian statistics may offer considerable advantages over traditional frequentist 


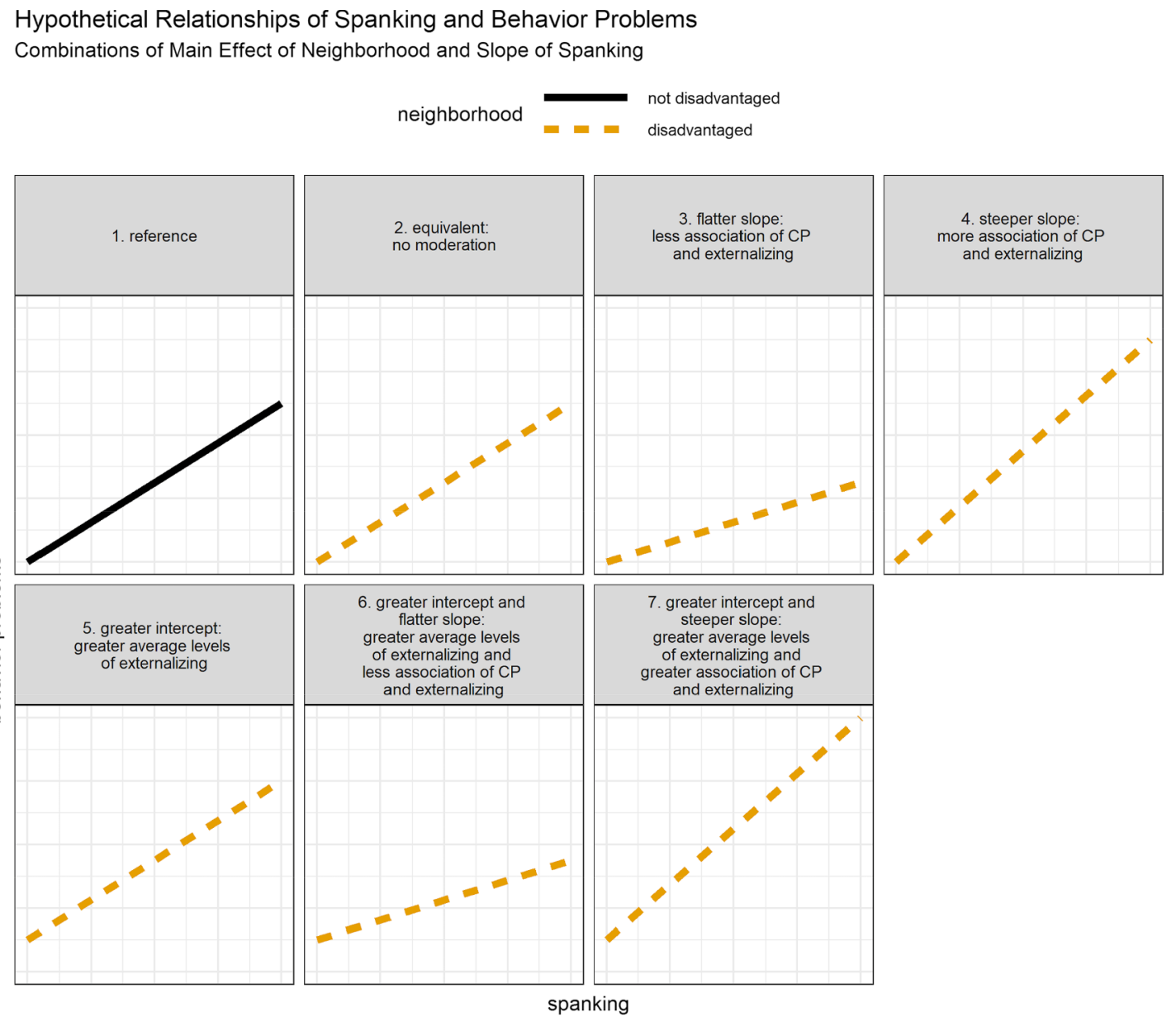

Fig. 1. Hypothetical Relationships of Physical Punishment and Behavior Problems.

statistics. Because the frequentist paradigm associates probability with long-run relative frequency, a p-value greater than 0.05 can only lead a researcher to fail to reject (rather than accept) the null hypothesis (Gigerenzer et al., 2004). On the other hand, according to the Bayesian paradigm, a credible interval for a particular parameter of interest that encompasses zero can inform a researcher that the null hypothesis is preferred over any other alternative (Kruschke, 2011). Thus, the Bayesian paradigm may provide researchers with a more literal and intuitive form of equivalence testing, allowing researchers to state whether the data actually favor the null hypothesis.

Bayesian equivalence testing could be particularly important when attempting to address research questions that have yielded conflicting results in the literature. For example, under a frequentist paradigm, some researchers have rejected the proposition that the relationship between physical punishment and child externalizing behavior is consistent across neighborhoods (Eamon, 2002), while others have failed to reject this hypothesis (Grogan-Kaylor, 2005; Ma et al., 2020). Because the Bayesian paradigm is not inherently seeking to reject or fail-to-reject a hypothesis-and, instead, provides probability distributions for parameters of interest-Bayesian statistics may help researchers to more accurately conclude that a moderating effect does not exist (Rouder et al., 2009). Indeed, the p-value under the Bayesian paradigm would reflect the probability of the absence of a moderating effect, given the data (van de Schoot et al., 2014).

\section{Methods}

\subsection{Sample}

The sample for the current study is drawn from the Fragile Families and Child Wellbeing Study (FFCWS). The FFCWS is a diverse community-based cohort study of new births in urban areas. Families were recruited to participate in the FFCWS in hospitals located in 20 U.S. cities with populations over 200,000 at the time of their focal child's birth between 1998 and 2000. The baseline core interview (Wave 1) was administered in-person to both parents in hospitals immediately after the child's birth and assessed a wide range of variables that have possible associations with family wellbeing such as demographics, health, and neighborhood conditions. Subsequent core interviews were conducted over the phone when the focal child was age 1 (Wave 2), age 3 (Wave 3), age 5 (Wave 4), and age 9 (Wave 5). Families who responded to the Wave 3 and Wave 4 core interviews were also invited to participate in a supplemental In-Home Longitudinal Study of PreSchool Aged Children (In-Home study hereafter) that collected both observational and survey data on parenting, child development, and neighborhood conditions at Wave 3 and Wave 4 (see Reichman, Teitler, Garfinkel, \& McLanahan, 2001 for a full description of the FFCWS).

Our analysis sample was limited to families who participated in the core interviews and In-Home studies at Wave 3 and Wave 4 during which the study outcome, child externalizing behavior, and the main predictors, maternal physical punishment and neighborhood risk, as well as the control variables included in our analyses were assessed $(N=2,718)$. 


\section{Measures}

\subsection{Child externalizing behavior}

The Externalizing Behavior subscale in the Child Behavior Checklist (Achenbach, 1991; 1992) assessed externalizing behavior. At Wave 3, mothers rated their child's behavior at approximately 3 years of age using 15 items in the $\mathrm{CBCL} / 2-3$ Externalizing Behavior subscale (alpha $=0.88$ ) with items such as "Child is defiant," "Child gets in many fights," and "Child hits others" $(0=$ not true, $1=$ somewhat or sometimes true, 2 = very true or often true). At Wave 4 (child age 5), mothers responded to 20 items in the CBCL/4-18 Externalizing Behavior subscale (alpha $=0.86$ ) with items such as "Child is cruel, bullies and shows meanness to others," "Child destroys his/her own things," and "Child physically attacks people" using the same ordinal scale that was used at Wave 3. The average of the items represented the externalizing behavior problem scores at Wave 3 and Wave 4 .

\subsection{Mother's physical punishment}

Mother's physical punishment at child age 3 was measured during the Wave 3 core interview by asking the following item to mothers: "Sometimes children behave pretty well and sometimes they don't. In the past month, have you spanked (child) because (he/she) was misbehaving or acting up?" $(0=$ no, $1=$ yes $)$.

\subsection{Neighborhood risk}

The Neighborhood Environment for Children Rating Scales (Coulton, Korbin, \& Su, 1996) measured neighborhood risk factors during the Wave 3 In-Home assessment. Mothers rated their neighborhood conditions on eight items such as the presence of drug dealers, gang activity, and unemployed adults loitering. Cronbach's alpha for this measure in this data was 0.93 .

\subsection{Control variables}

Child sex $(1=$ boy, $2=$ girl $)$ and race $(1=$ White, $2=$ Black, $3=$ Hispanic, $4=$ Other) were measured at the baseline core interview (Wave 1). Family income was assessed by asking the mother to report their household's income in the past year at Wave 3 .

\section{Analytic strategy}

To develop our Bayesian priors, we took into account a recent metaanalytic review summarizing decades of empirical research on physical punishment has found a consistent association of the use of corporal punishment with undesirable child outcomes (Gershoff \& GroganKaylor, 2016a). Notably, Gershoff and Grogan-Kaylor (2016a) found little evidence that there was variation in the associations between physical punishment and child outcomes by methodological characteristics of the study, or by the study population. Thus we use Gershoff and Grogan-Kaylor's estimates of the effect of physical punishment to develop a prior for our regression analysis.

Gershoff and Grogan-Kaylor (2016a) found that parental use of physical punishment was associated with detrimental child outcomes with a Cohen's d of 0.33. Put differently, the estimated level of undesirable outcomes among spanked children were 0.33 standard deviations higher than non-spanked children. Therefore, in order to incorporate prior beliefs into our statistical model, we first standardized the outcome measure of externalizing behavior problems, so that differences in externalizing behavior problems would be expressed in standard deviation units. We also coded physical punishment as a dichotomous variable, so that the regression coefficient would encode the differences between spanked and non-spanked children. The confidence interval for Gershoff and Grogan-Kaylor's (2016a) estimate of d was
$(0.29,0.38)$. Our prior in this analysis has a slightly wider standard deviation to allow for slightly more uncertainty around this estimate.

Cohen's $d=.33 \Rightarrow$

$z_{\text {externalizingbehavior }}=\beta_{0}+\beta_{1}$ physical punishment $t_{1 / 0}+\ldots$

Prior: $\beta_{1} \sim N(.33,1.0)$

Our full regression model was thus:

$z_{\text {externalizing behavior }}=\beta_{0}+\beta_{1}$ physical punishment $1_{10}+\beta_{2}$ neighborhood + $\beta_{3}$ physical punishment $t_{10}$ neighborhood $+\Sigma \beta_{k}$ covariates $_{k}+e_{i}$

Here the dependent variable $z$ was the standardized measure of externalizing behavior problems. $\beta_{0}$ was an intercept term. $\beta_{1}$ was a regression coefficient for a dichotomous indicator variable measuring physical punishment. $\beta_{2}$ was the regression coefficient for neighborhood conditions. $\beta_{3}$ was the regression coefficient for the interaction of neighborhood conditions and physical punishment and $\Sigma \beta_{k}$ represented a set of regression coefficients for other covariates in the model. $e_{i}$ was an error term. To examine the effect that incorporating this prior had on the results, we first estimated a model with uniformative default priors for all regression coefficients, and then estimated a model in which we imposed this more informative regression prior on $\beta_{1}$ (Depaoli \& van de Schoot, 2017).

\section{Results}

\subsection{Descriptive statistics}

The analytic sample for the current study $(N=2,718)$ includes mothers and children from the FFCWS study at Wave 3 and Wave 4 who had complete data on all variables of interest. The FFCWS study oversampled unmarried parents, therefore, the current study sample had a mean income of $\$ 37,509(S D=\$ 43,869)$ and was comprised of individuals who identified as non-Hispanic Black, 47.6\%, Hispanic, $27.3 \%$, White, $21.1 \%$, and 'Other race' made up $3.8 \%$ of the sample. Sex of children in the sample was almost evenly split (52.4\% male). Just over half $(52.2 \%)$ of mothers reported physically punishing their child at the age of 3. Mean level of child externalizing behavior was 0.62 at age 3 and 0.44 at age 5 . Mean of neighborhood risks at age 3 was 1.80 (range 1-4). All descriptive statistics are presented in Table 1.

\section{Bayesian regression}

Two Bayesian regression models were carried out: one naïve model that did not specify mean and standard deviation priors, and instead employed default uninformative priors (Model 1) and one model specifying prior mean and standard deviation scores for physical punishment from extant research (Model 2) (Gershoff \& Grogan-Kaylor, 2016a). As shown in Table 2, the mean, standard deviation, and credible interval scores of the two Bayesian models were identical to the

Table 1

Descriptive Statistics $(N=2718)$.

\begin{tabular}{lll}
\hline Measures & & Mean or Percent \% \\
\hline Child Sex & Male & \\
& & $52.44 \%$ \\
Race & Black & \\
& Hispanic & $47.63 \%$ \\
& White & $27.30 \%$ \\
& Other & $21.09 \%$ \\
Income & & $3.97 \%$ \\
Externalizing Behavior, Age 3 & Mean: $\$ 37,509(S D: \$ 43,869)$ \\
\multicolumn{2}{l}{ Mother's Physical Punishment, Age 3 } & Mean: $0.62(S D: 0.36)$ \\
Neighborhood Risks & $52.15 \%$ \\
\hline
\end{tabular}

Note. $\mathrm{SD}=$ Standard Deviation. 
Table 2

Bayesian Regression Models for Child Externalizing Behavior at Age $5(N=2718)$.

\begin{tabular}{|c|c|c|c|c|c|c|c|c|}
\hline \multirow[b]{2}{*}{ Measure } & \multicolumn{4}{|c|}{ Model 1: Without Priors } & \multicolumn{4}{|c|}{ Model 2: With Priors } \\
\hline & Mean & SD & CI $(95 \%)$ & & Mean & SD & CI (95\%) & \\
\hline $\begin{array}{l}\text { Child Sex } \\
\text { Mother's Race (= White) }\end{array}$ & -0.015 & 0.031 & -0.076 & 0.045 & -0.015 & 0.031 & -0.076 & 0.045 \\
\hline Black & -0.084 & 0.042 & -0.166 & -0.002 & -0.085 & 0.042 & -0.166 & -0.003 \\
\hline Hispanic & -0.088 & 0.046 & -0.178 & 0.004 & -0.088 & 0.046 & -0.178 & 0.004 \\
\hline Other & -0.014 & 0.090 & -0.193 & 0.164 & -0.014 & 0.090 & -0.191 & 0.161 \\
\hline Externalizing Behavior, Age 3 & 1.321 & 0.046 & 1.229 & 1.412 & 1.320 & 0.046 & 1.229 & 1.412 \\
\hline Income & -0.006 & 0.004 & -0.014 & 0.001 & -0.006 & 0.004 & -0.014 & 0.001 \\
\hline Physical Punishment, Age 3 & 0.118 & 0.031 & 0.057 & 0.179 & 0.118 & 0.032 & 0.056 & 0.181 \\
\hline Neighborhood Risks & 0.069 & 0.019 & 0.032 & 0.106 & 0.069 & 0.019 & 0.033 & 0.106 \\
\hline
\end{tabular}

Note. $\mathrm{SD}=$ Standard Deviation, $\mathrm{CI}=$ Credible Interval.

second decimal point. Results for both models are available in Table 2; however, we will report on the Bayesian model results (Model 2) that specified priors for the mean and standard deviations of the regression parameter for physical punishment.

The interpretations of the Bayesian model results are primarily derived from the parameter estimate mean scores and the $95 \%$ credible interval of the particular parameter estimate mean. Based on a two-tail distribution, mean estimates with $95 \%$ credible intervals that exclude zero suggest there is a $95 \%$ probability that the estimate is not zero. For example, children's externalizing behavior at age 3 appears to have an effect on externalizing behavior at age 5 , such that externalizing behavior at age 3 predicts higher levels of externalizing behavior at age 5 (mean $=1.321,95 \% \mathrm{CI}=[1.229,1.412]$ ). Similarly, even after accounting for children's prior externalizing behavior, mother's physical punishment at child age 3 demonstrated an effect on children's externalizing behavior at age 5 (mean $=0.118,95 \% \mathrm{CI}=[0.056$, $0.181]$ ). The positive coefficient suggests that mother's physical punishment at age 3 is related to higher levels of children's externalizing behavior at age 5 , even after controlling for pre-existing externalizing behavior. Similarly, neighborhood risk, even after accounting for children's prior externalizing behavior and mother's physical punishment, appears to elevate children's externalizing behavior at age 5. In contrast, the credible interval for the interaction of physical punishment and neighborhood risk included 0 (mean $=0.051,95 \% \mathrm{CI}=[-0.017$, $0.119]$ ), suggesting that physical punishment was associated with increases in externalizing behavior regardless of neighborhood context.

\section{Discussion}

To begin the discussion of study results, we return to our initial conceptualization of slopes and intercepts with regard to the associations of physical punishment, neighborhood risk, with children's externalizing behavior problems. There was a positive slope for the physical punishment coefficient: as expected, and consistent with numerous prior studies (Gershoff \& Grogan-Kaylor, 2016a), physical punishment was associated with subsequent increases in children's behavior problems. The second part of our conceptualization was to consider the main effects of neighborhood risk, as well as the way in which neighborhood context might modify the association of physical punishment with children's behavior problems. The main effect of neighborhood risk had a credible interval that excluded zero. Put more intuitively, the current results suggest an association of neighborhood risk with increases in children's externalizing behavior, net of other covariates in the model.

In line with previous studies (Ma, Grogan-Kaylor, \& Lee, 2018; Margolin \& Gordis, 2000), this association may be explained through several hypotheses that take into account both direct and indirect effects of disadvantaged neighborhood conditions on children's behavioral outcomes. For example, social learning theory posits that when children are exposed to the violent environment, they are more prone to using aggressive methods to treat others by modeling and accepting aggression as a socially desirable behavior (Bandura, 1973). Therefore, children may imitate aggressive behaviors and obtain violent behavioral norms from interpersonal relationships that are learned in during their daily routine. Secondly, at a more macro level, neighborhood risks may exacerbate parents' stress levels, and parents may become less capable of managing children's behavior. Less optimal parenting may contribute to escalating children's antisocial behavior (Gorman-Smith, Tolan, \& Henry, 2000). Lastly, there may be indirect effects as well. Children who reside in high-risk environments may have limited access to community resources including playgrounds, childcare services, and other institutions that may help children's healthy development (Leventhal \& Brooks-Gunn, 2000). Lack of access to institutional resources in neighborhoods may be particularly important to consider given the young age of the children involved in the current study. The current study extends prior research on neighborhood effects that largely focused on outcomes of older children with the use a sophisticated statistical technique to replicate similar patterns with young children, beginning well before school age.

To address the key research question in the current study, the interaction of physical punishment and neighborhood risk had a credible interval that included 0 , which indicates that neighborhood risk was not associated with changes in the slope connecting physical punishment with externalizing behavior. Thus, the results of the Bayesian analysis are consistent with prior studies (e.g., Ma et al., 2020) and indicate that both physical punishment and neighborhood risk have direct associations with child behavior problems. Physical punishment appears to have equivalent effects on increases in child behavior problems across neighborhood contexts.

\section{Implications for policy and practice}

The current study adds to the growing literature that indicates the undesirable effects of physical punishment on children's behavior and suggests that interventions and policies that seek to reduce the use of physical punishment are warranted. At the same time, the findings herein add to a growing body of research that suggests the undesirable effects of physical punishment are largely universal and independent of context, meaning that children in various neighborhood conditions and cultural contexts stand to benefit from reductions in exposure to parental physical punishment (Grogan-Kaylor et al., 2018). Recognizing the accumulating evidence on the adverse effects of physical punishment on child well-being regardless of contexts, professional organizations such as the American Academy of Pediatrics have recently issued policy statements advising parents and caregivers to avoid the use of physical punishment to children (Sege \& Siegel, 2018).

Several recent publications review promising intervention strategies to reduce parents' use of physical punishment (Gershoff et al., 2017; Gershoff \& Lee, 2020). There are evidence-based interventions to help parents reduce the use of physical punishment at the universal, 
selected, and indicated levels of prevention (Gershoff, et al., 2019). For example, Triple $\mathrm{P}$ uses a universal multi-level approach to promoting positive parenting behaviors and child wellbeing (Prinz, 2020). Play Nicely is a brief intervention utilized in pediatric waiting rooms that has shown significant effects in reducing parents' intentions to use physical punishment (Scholer, 2020). Another parenting resource, Positive Discipline in Everyday Parenting (Durrant, 2020), addresses the universal goal of parents across the globe to support their children's healthy development and may serve as an effective resource for discussions around alternative ways to correct children's misbehavior.

In terms of larger policy implications, the current findings suggest that large-scale policy interventions to reduce the use of physical punishment may also benefit the wellbeing of many children. As of 2020, 59 countries around the world have instituted country level bans against the use of physical punishment (https:// endcorporalpunishment.org/).

\section{Limitations}

The findings presented herein should be interpreted with the following limitations in mind. First, as is the case with any observational study, the causal nature of the relationship of physical punishment with children's behavior cannot be fully established. Second, the generalizability of the study findings is limited to socio-economically disadvantaged families residing in large U.S. cities. Finally, the findings are subject to social desirability bias, as the main predictors and the outcome relied on mother's self-report. It is possible that mothers have under-reported their use of physical punishment, their child's behavioral issues, as well as the risk factors in their neighborhood. Notwithstanding these limitations, the use of the Bayesian paradigm that incorporates prior knowledge into the analyses strengthens the current findings to provide more accurate evidence against the argument that the association of physical punishment with children's behavior is dependent on neighborhood contexts.

\section{Future research}

Research shows that the association between physical punishment and child socioemotional development is seen in countries across the world. Specifically, in a study of over 215,000 children from 62 lowand middle- income countries, there was a significant negative association between physical punishment and child socioemotional development in $95 \%$ of the countries and a null finding (no association) in $5 \%$ of the countries studies. In no cases was there a positive association between physical punishment and child socioemotional development (Pace, Lee, \& Grogan-Kaylor, 2019). However, it is worth noting that the mechanisms that link physical punishment to child socioemotional development may well be culturally determined. Thus, the finding of the current study - that neighborhood factors do not moderate the associations between physical punishment and child wellbeing-may be U.S. specific. Future research may wish to consider whether the mechanisms linking physical punishment to child wellbeing differ across countries and cultures.

\section{Conclusion}

The results of the current study add to the literature suggesting that physical punishment is associated with increases in child behavior problems. Physical punishment appears to be equally disadvantageous for children, irrespective of the level of risk factors in neighborhoods. Our findings coincide with the 2018 AAP policy statement (Sege and Siegel, 2018), which encourages parents to avoid the use of physical punishment. Our findings also suggest that most families in the U.S., regardless of neighborhood risk, may benefit from interventions that provide parents with non-physical discipline strategies.

Author Statement
Dr. Grogan-Kaylor conceptualized and designed the study, carried out the analyses, drafted the initial manuscript, and reviewed and revised the manuscript.

Ms. Castillo, Dr. Ma, Ms. Ward, Dr. Lee, Mr. Pace and Ms. Park contributed substantial intellectual content to the writing of the manuscript and reviewed and revised the manuscript.

All authors approved the final manuscript as submitted and agree to be accountable for all aspects of the work.

\section{References}

Achenbach, T. M. (1991). Integrative guide for the 1991 CBCL/4-18, YSR, and TRF profiles. Burlington, VT: Department of Psychiatry, University of Vermont.

Achenbach, T. M. (1992). Manual for the Child Behavior Checklist/2-3 and 1992 profile Burlington, VT: Department of Psychiatry, University of Vermont.

Bandura, A. (1973). Aggression: A social learning analysis. Englewood Cliffs, NJ: Prentice Hall.

Baumrind, D., Larzelere, R. E., \& Cowan, P. A. (2002). Ordinary physical punishment: Is it harmful? Comment on Gershoff (2002). Psychological Bulletin, 128(4), 511-580. https://doi.org/10.1037/0033-2909.128.4.580.

Belsky, J. (1993). Etiology of child maltreatment: A developmental ecological analysis. Psychological bulletin, 114(3), 413. https://doi.org/10.1037/0033-2909.114.3.413.

Benjet, C., \& Kazdin, A. E. (2003). Spanking children: The controversies, findings, and new directions. Clinical psychology review, 23(2), 197-224. https://doi.org/10.1016/ S0272-7358(02)00206-4.

Berlin, L. J., Ispa, J. M., Fine, M. A., Malone, P. S., Brooks-Gunn, J., Brady-Smith, C., .. Bai, Y. (2009). Correlates and consequences of spanking and verbal punishment for low-income white, african american, and mexican american toddlers. Child Development, 80(5), 1403-1420. https://doi.org/10.1111/j.1467-8624.2009. 01341.x.

Coulton, C., Korbin, J., \& Su, M. (1996). Measuring neighborhood context for young children in an urban area. American Journal of Community Psychology, 24, 5-32.

Darling, N., \& Steinberg, L. (1993). Parenting style as context: An integrative model. Psychological Bulletin, 113(3), 487-496. https://doi.org/10.1037/0033-2909.113.3. 487.

Deater-Deckard, K., Dodge, K. A., Bates, J. E., \& Pettit, G. S. (1996). Physical discipline among African American and European American mothers: Links to children's externalizing behaviors. Developmental Psychology. 32(6), 1065-1072. https://doi.org/ 10.1037/0012-1649.32.6.1065.

Depaoli, S., \& van de Schoot, R. (2017). Improving transparency and replication in Bayesian statistics: The WAMBS-Checklist. Psychological Methods, 22(2), 240-261. https://doi.org/10.1037/met0000065.

Dunson, D. B. (2001). Commentary: Practical advantages of Bayesian analysis of epidemiological data. American Journal of Epidemiology, 153(12), 1222-1226. https://doi. org/10.1093/aje/153.12.1222.

Durrant, J. E. (2020). Positive Discipline in Everyday Parenting. In E. T. Gershoff, \& S. J Lee (Eds.). Ending the Physical Punishment of Children: A Guide for Clinicians and Practitioners (pp. 89-97). Washington, DC: American Psychology Association.

Eamon, M. K. (2002). Poverty, Parenting, Peer, and Neighborhood Influences on Young Adolescent Antisocial Behavior. Journal of Social Service Research. https://doi.org/10. 1300/J079v28n01_01.

Earls, F., McGuire, J., \& Shay, S. (1994). Evaluating a community intervention to reduce the risk of child abuse: Methodological strategies in conducting neighborhood surveys. Child Abuse \& Neglect, 18(5), 473-485. https://doi.org/10.1016/0145-2134(94) 90031-0.

Friedson, M. (2016). Authoritarian parenting attitudes and social origin: The multigenerational relationship of socioeconomic position to childrearing values. Child Abuse \& Neglect, 51, 263-275. https://doi.org/10.1016/j.chiabu.2015.10.001.

Furstenberg, F. F. (1993). How families manage risk and opportunity in dangerous neighborhoods. In W. J. Wilson (Ed.). Sociology and the public agenda (pp. 231-258). Sage.

Garbarino, J., Kostelny, K., \& Barry, F. (1997). Value transmission in an ecological context: The high-risk neighborhood. In J. E. Grusec, \& L. Kuczynski (Eds.). Parenting and children's internalization of values: A handbook of contemporary theory (pp. 307-332). New York, NY: John Wiley \& Sons Inc.

Gershoff, E. T., \& Grogan-Kaylor, A. (2016a). Spanking and child outcomes: Old controversies and new meta-analyses. Journal of Family Psychology, 30(4), 453-469. https://doi.org/10.1037/fam0000191.

Gershoff, E. T., \& Grogan-Kaylor, A. (2016b). Race as a moderator of associations between spanking and child outcomes. Family Relations, 65, 490-501. https://doi.org/10. 1111 /fare. 12205.

Gershoff, E. T., \& Lee, S. J. (2020). Ending the Physical Punishment of Children: A Guide for Clinicians and Practitioners. Washington, DC: American Psychology Association.

Gershoff, E. T., Lee, S. J., \& Durrant, J. E. (2017). Promising intervention strategies to reduce parents' use of physical punishment. Child Abuse \& Neglect. https://doi.org/10 1016/j.chiabu.2017.01.017.

Gershoff, E. T., Sattler, K. M., \& Ansari, A. (2018). Strengthening causal estimates for links between spanking and children's externalizing behavior problems. Psychological science, 29(1), 110-120.

Gigerenzer, G., Krauss, S., \& Vitouch, O. (2004). The null ritual: What you always wanted to know about significance testing but were afraid to ask. In D. Kaplan (Ed.). The sage handbook of quantitative methodology for the social sciences (pp. 391-408). Thousand 
Oaks, CA: Sage.

Gorman-Smith, D., Tolan, P. H., \& Henry, D. B. (2000). A developmental-ecological model of the relation of family functioning to patterns of delinquency. Journal of Quantitative Criminology, 16(2), 169-198. https://doi.org/10.1023/A:1007564505850.

Grogan-Kaylor, A., Ma, J., Lee, S. J., Castillo, B., Ward, K. P., \& Klein, S. (2018). Using Bayesian analysis to examine associations between spanking and child externalizing behavior across race and ethnic groups. Child Abuse \& Neglect, 86, 257-266. https:// doi.org/10.1016/j.chiabu.2018.10.009.

Grogan-Kaylor, A. (2005). Relationship of corporal punishment and antisocial behavior by neighborhood. Archives of Pediatrics and Adolescent Medicine, 159(10), 938-942. https://doi.org/10.1001/archpedi.159.10.938.

Jackman, S. D. (2009). Bayesian Analysis for the Social Sciences. New York: Wiley.

Kruschke, J. K. (2011). Doing Bayesian data analysis: A tutorial with $R$ and BUGS. Burlington, MA: Academic Press.

Kruschke, J. K., \& Liddell, T. M. (2018). Bayesian data analysis for newcomers. Psychonomic Bulletin \& Review, 25, 155-177. https://doi.org/10.3758/s13423-0171272-1.

Lakens, D., Scheel, A. M., \& Isager, P. M. (2018). Equivalence testing for psychological research: A tutorial. Advances in Methods and Practices in Psychological Science, 1(2), 259-269. https://doi.org/10.1177/2515245918770963.

Lee, S. J., Altschul, I., \& Gershoff, E. T. (2013). Does warmth moderate longitudinal as sociations between maternal spanking and child aggression in early childhood? Developmental Psychology, 49(11), 2017-2028. https://doi.org/10.1037/a0031630.

Leventhal, T., \& Brooks-Gunn, J. (2000). The neighborhoods they live in: the effects of neighborhood residence on child and adolescent outcomes. Psychological Bulletin, 126(2), 309-337. http://dx.doi.org/10.1037/0033-2909.126.2.309.

Ma, J., Grogan-Kaylor, A., \& Lee, S. J. (2020). Does community violence exposure moderate the associations between maternal spanking and early child behavior problems?. Aggressive behavior.

Ma, J., Grogan-Kaylor, A., \& Lee, S. J. (2018). Associations of neighborhood disorganization and maternal spanking with children's aggression: A fixed-effects regression analysis. Child Abuse \& Neglect, 76, 106-116. https://doi.org/10.1016/j. chiabu.2017.10.013.

Margolin, G., \& Gordis, E. B. (2000). The effects of family and community violence on children. Annual Review of Psychology, 51(1), 445-479. https://doi.org/10.1146/ annurev.psych.51.1.445.

McLoyd, V. C. (1998). Socioeconomic disadvantage and child development. The American Psychologist, 53(2), 185-204. https://doi.org/10.1037/0003-066X.53.2.185.

Morrison, D. E., \& Henkel, R. E. (1970). The significance test controversy. New Brunswick: Transaction Publishers.

Pace, G. T., Lee, S. J., \& Grogan-Kaylor, A. (2019). Spanking and young children's socioemotional development in low- and middle-income countries. Child Abuse \& Neglect, 88, 84-95. https://doi.org/10.1016/j.chiabu.2018.11.003.

Prinz, R. J. (2020). Triple P - Positive Parenting Program. In E. T. Gershoff, \& S. J. Lee
(Eds.). Ending the Physical Punishment of Children: A Guide for Clinicians and Practitioners (pp. 133-143). Washington, DC: American Psychology Association.

Reichman, N. E., Teitler, J. O., Garfinkel, I., \& McLanahan, S. S. (2001). Fragile Families: Sample and design. Children and Youth Services Review, 23(4-5), 303-326. https:// doi.org/10.1016/S0190-7409(01)00141-4.

Raudenbush, S. W., \& Bryk, A. S. (2002). Hierarchical linear models: Applications and data analysis methods. Thousand Oaks, CA: Sage Publications.

Rohner, R. P. (2004). The parental "acceptance-rejection syndrome": Universal correlates of perceived rejection. American Psychologist. https://doi.org/10.1037/0003-066X. 59.8 .830$.

Rouder, J. N., Speckman, P. L., Sun, D., Morey, R. D., \& Iverson, G. (2009). Bayesian t tests for accepting and rejecting the null hypothesis. Psychonomic Bulletin \& Review, 16, 225-237. https://doi.org/10.3758/PBR.16.2.225.

Scholer, S. (2020). Play Nicely. In E. T. Gershoff, \& S. J. Lee (Eds.). Ending the Physical Punishment of Children: A Guide for Clinicians and Practitioners (pp. 49-61). Washington, DC: American Psychology Association.

Simons, R. L., Lin, K.-H., Gordon, L. C., Brody, G. H., Murry, V., \& Conger, R. D. (2002). Community differences in the association between parenting practices and child conduct problems. Journal of Marriage and Family, 64(2), 331-345.

Simons, R. L., Whitbeck, L. B., Conger, R. D., \& Chyi-In, W. (1991). Intergenerational Transmission of Harsh Parenting. Developmental Psychology, 27(1), 159-171. https:// doi.org/10.1037/0012-1649.27.1.159.

Sege, R. D., \& Siegel, B. S. (2018). Effective Discipline to Raise Healthy Children. Pediatrics, 142(6), e20183112. https://doi.org/10.1542/peds.2018-3112.

Stacks, A., Oshio, T., Gerard, J., \& Roe, J. (2009). The moderating effect of parental warmth on the association between spanking and child aggression: A longitudinal approach. Infant and Child Development, 18(2), 178-194. https://doi.org/10.1002/ icd.596.

Sterne, J. A. C., Smith, G. D., \& Cox, D. R. (2001). Sifting the evidence-what's wrong with significance tests? BMJ, 322(7280), 226. https://doi.org/10.1136/bmj.322. 7280.226 .

van de Schoot, R., Kaplan, D., Denissen, J., Asendorpf, J. B., Neyer, F. J., \& Aken, M. A. G. (2013). A gentle introduction to Bayesian analysis: Applications to developmental research. Child Development, 85(3), 842-860. https://doi.org/10.1111/cdev.12169.

Vanpaemel, W. (2010). Prior sensitivity in theory testing: An apologia for the Bayes factor. Journal of Mathematical Psychology, 54, 491-498. https://doi.org/10.1016/j. jmp.2010.07.003.

Ward, K. P., Lee, S. J., Limb, G. E., \& Grogan-Kaylor, A. (2019). Physical punishment and child externalizing behavior: Comparing American Indian, White, and African American children. Journal of Interpersonal Violence (advanced online publication). https://doi.org/10.1177/0886260519861678.

Ward, K. P., Lee, S. J., Pace, G. T., Grogan-Kaylor, A., \& Ma, J. (2019). Attachment style and the association of spanking and child externalizing behavior. Academic Pediatrics (advanced online publication). https://doi.org/10.1016/j.acap.2019.06.017. 